\title{
The long-term safety and efficacy of opioids: A survey of 84 selected patients with intractable chronic noncancer pain
}

\author{
C Peter N Watson MD FRCPC ${ }^{1}$, Judy Watt-Watson RN PhD², Mary Chipman $\mathrm{MA}^{3}$
}

CPN Watson, J Watt-Watson, M Chipman. The long-term safety and efficacy of opioids: A survey of 84 selected patients with intractable chronic noncancer pain. Pain Res Manage 2010;15(4):213-217.

BACKGROUND: The use of opioids for chronic noncancer pain (CNCP) remains controversial. Despite a number of randomized controlled trials showing efficacy and safety in the short term, long-term data are limited.

OBJECTIVE: To survey a selected cohort of patients with intractable CNCP with regard to long-term efficacy and safety of opioids.

METHODS: The present study reports long-term results from a survey of 84 patients with CNCP. The majority of patients had neuropathic pain, were treated with opioids and were followed every three months for a median of 8.4 years. Outcomes examined were pain severity, adverse effects, pain relief, satisfaction, mood, problematic opioid use, tolerance, physical dependency, functional status, health-related quality of life, immune status, sexual function, morbidity and mortality. Measures included a numerical rating scale, the Hospital Anxiety and Depression Scale, Brief Pain Inventory interference scale, Pain Disability Index and Short-Form Health Survey 12, version 2.

RESULTS AND CONCLUSIONS: Both long- and short-acting opioids were reported to be effective, with few significant long-term adverse effects in many subjects in the present selected cohort. The majority of patients reported at least $50 \%$ or greater pain relief and a moderate improvement in disability. Functional status and health-related quality of life scores were not severely affected. Problematic opioid use, tolerance and serious adverse effects, including constipation, were not major issues. The authors emphasize that the results obtained in the present selected group may not be generalizable to all CNCP patients in whom opioids are being initiated.

Key Words: Chronic noncancer pain; Long term; Neuropathic pain; Opioids

A number of randomized controlled trials (RCTs) (1-9) have shown the efficacy and safety of opioids in chronic noncancer pain $(\mathrm{CNCP})$ in the short term - many of which were conducted in patients with neuropathic pain (NP). However, the long-term use of opioids for these conditions remains controversial given the concerns about long-term efficacy and safety. Efficacy concerns are pain relief, tolerance and health-related quality of life (HRQL). Safety concerns include the risk of problematic use and diversion, increased pain sensitivity such as hyperalgesia with high doses, potential effects on the immune and endocrine systems, cognitive/affective changes and mortality (10-17).

Minimal data are available regarding the long-term follow-up of CNCP patients treated with opioids. It is extremely difficult

\section{L'innocuité et l'efficacité à long terme des opioïdes : Une enquête auprès de 84 patients sélectionnés ayant des douleurs chroniques non cancéreuses réfractaires}

HISTORIQUE : Le recours aux opioïdes pour traiter des douleurs chroniques non cancéreuses chroniques (DCNC) demeure controversé. Malgré plusieurs essais aléatoires et contrôlés qui en démontrent l'efficacité et l'innocuité à court terme, les données à long terme sont limitées.

OBJECTIF : Sonder une cohorte sélectionnée de patients ayant des DCNC réfractaires au sujet de l'efficacité et de l'innocuité à long terme des opioïdes.

MÉTHODOLOGIE : La présente étude rend compte des résultats à long terme d'une enquête auprès de 84 patients ayant des DCNC. La majorité avaient des douleurs névropathiques, étaient traités aux opioïdes et étaient suivis tous les trois mois pendant une médiane de 8,4 ans. Les issues examinées étaient la gravité de la douleur, les effets indésirables, le soulagement de la douleur, la satisfaction, les humeurs, la consommation problématique d'opiö̈des, la tolérance, la dépendance physique, l'état fonctionnel, la qualité de vie liée à la santé, l'état immunitaire, la fonction sexuelle, la morbidité et la mortalité. Les mesures incluaient une échelle d'évaluation numérique, l'échelle d'anxiété et de dépression en milieu hospitalier, l'échelle d'interférence du bref inventaire de la douleur, l'indice d'incapacité liée à la douleur et la courte enquête de santé 12, version 2. RÉSULTATS ET CONCLUSIONS : Tant les opioïdes à action prolongée qu'à action brève étaient efficaces et causaient peu d'effets indésirables à long terme chez de nombreux sujets de la cohorte sélectionnée. La majorité des patients déclaraient un soulagement de la douleur d'au moins $50 \%$ et une diminution modérée de l'incapacité. Les indices d'état fonctionnel et de qualité de vie liée à la santé n'étaient pas touchés de manière marquée. L'utilisation problématique d'opioïdes, la tolérance et les graves effets indésirables, y compris la constipation, ne constituaient pas de gros problèmes. Les auteurs ont souligné que les résultats obtenus auprès du présent groupe sélectionné ne peuvent peut-être pas généralisés à tous les patients ayant des DCNC chez qui on amorce les opioïdes.

to conduct an RCT over a long period of time, and data in this regard are both observational (18-22) and epidemiological (23-25). The present observational study provides efficacy and safety data from an undoubtedly selected population of patients with intractable CNCP of mostly neuropathic origin.

\section{METHODS}

Study design, setting and participants

In the present longitudinal, observational, descriptive study, data were collected between September 1 and December 31, 2007, from 84 patients with intractable, daily, severe CNCP, who were treated with opioids for at least one year, were being assessed every three months and were living in the community. In the present study, 'intractable' meant that the patients were

${ }^{1}$ Faculty of Medicine; ${ }^{2}$ Lawrence S Bloomberg Faculty of Nursing; ${ }^{3}$ Dalla Lana School of Public Health, University of Toronto, Toronto, Ontario

Correspondence: Dr CPN Watson, 1 Sir Williams Lane, Toronto, Ontario M9A 1T8. Telephone 416-239-3494, fax 416-239-6365,

e-mail peter.watson@utoronto.ca 
TABLE 1

Diagnostic categories of the 84 surveyed subjects

\begin{tabular}{lc}
\hline Diagnostic category & Patients, $\mathbf{n}$ \\
\hline Neuropathic pain & 71 \\
Back and leg nerve roots & 24 \\
Neuropathic facial pain (excludes trigeminal neuralgia) & 18 \\
Postherpetic neuralgia & 2 \\
Peripheral neuropathy (diabetic, n=7; renal, n=1) & 8 \\
Complex regional pain syndrome II (causalgia) & 2 \\
Central pain (stroke, n=1; spinal cord injury, n=1; & 4 \\
$\quad$ syringomyelia, n=1; multiple sclerosis, $\mathrm{n}=1$ ) & \\
Neck and arm nerve roots (C6 and C7) & 3 \\
Postcoronary bypass incisional pain & 1 \\
Neuropathic pain in the pelvis or abdomen & 3 \\
Brachial plexus avulsion & 2 \\
Phantom limb pain & 3 \\
von Recklinghausen's disease peripheral neuropathic pain & 1 \\
Musculoskeletal pain (osteoarthritis, n=17; Crohn's disease, & 21 \\
$\mathrm{n}=1 ;$ osteomyelitis, $\mathrm{n}=1 ;$ rheumatoid arthritis, $\mathrm{n}=1 ;$ & \\
osteoporosis/compression, $\mathrm{n}=1$ ) & \\
Chronic headache & 4 \\
Other (postgastrectomy or abdominal pain) & 2 \\
Total &
\end{tabular}

There were 98 pain conditions in the 84 subjects. Some patients had more than one pain diagnosis

refractory to nonopioid medications, having had adequate trials of nonprescription analgesics, and at least two analgesic antidepressants (tricyclics and other antidepressants) and anticonvulsants (gabapentinoids and other anticonvulsants). Informed consent was obtained from all patients.

\section{Outcomes}

Baseline demographic data were obtained at the first visit, including age, sex, diagnosis, psychiatric history, personal and family history of addiction, previous treatments, pain severity (measured using a numerical rating scale [NRS] and a category scale of mild, moderate, severe and very severe), duration of pain, mood (NRS), disability (bedridden, capable of activities of daily living [ADL], working and ability to exercise), sleep (NRS), and concomitant medications. The convenience sample for the present survey included all eligible patients seen from September 1 to December 31, 2007. At the time of the survey, data were recorded regarding the duration of pain and related follow-up; opioids used and dose in morphine equivalents (MEs) (recorded using an equianalgesic table for chronic dosing); duration of opioid use; and length of time on stable opioid dosing. These data were entered in an SPSS database (SPSS Inc, USA) for analysis.

Pain severity was recorded on an NRS of 0 to 10 and a category scale of mild, moderate, severe and very severe, with and without opioids, and with usual activity over the previous week.

Adverse effects were recorded by the patient in an openended fashion and rated as tolerable or intolerable. A specific inquiry was made regarding the presence, tolerability and treatment of constipation. A question was asked regarding satisfaction with the pain relief and the tolerability of adverse effects. Depression and anxiety were rated using the Hospital Anxiety and Depression Scale (26). A cut-off score of 11 or greater was used to indicate probable anxiety and depression.

A record was kept of all instances of problematic opioid use. Tolerance was evaluated by determining the length of time a patient was on stable dosing. Physical withdrawal was assessed by a questionnaire that asked about the occurrence of withdrawal symptoms with missed doses.

Functional status was rated by the Brief Pain Inventory interference scale (BPI-I) (27) and the Pain Disability Index (PDI) $(28,29)$, as recommended for use in pain trials $(30)$. HRQL was assessed by the Short-Form Health Survey 12, version 2 (SF12v2) (31), a shorter, valid alternative to the much longer Short-Form Health Survey 36. A questionnaire was included to evaluate immune status by asking about any infections that had occurred over the previous year, using a list of common infections with an 'other' category (upper respiratory, urinary, pneumonia, gastrointestinal and other infections), and the number of occurrences. A questionnaire about sexual function using a 0 to 10 rating scale was administered, with 0 being the rating they would consider normal for them before the development of CNCP. Sexual function was also examined by the sexual function scale of the PDI.

\section{Statistical analysis}

Descriptive statistics were used to analyze the sample characteristics and diagnostic categories. Medians, SDs and proportions were used to summarize outcome variable data. Pearson correlations were used to examine relationships between interval variables.

\section{RESULTS}

\section{Participants and flow diagram}

A total of 84 patients with CNCP on opioids were being followed at three-month intervals in the autumn of 2007; these are the participants in the present survey. The median $( \pm \mathrm{SD})$ follow-up duration was $8.4 \pm 5.9$ years (range one to 24 years). The median duration on the same dose of opioid(s) was $3.5 \pm 3.0$ years (range one to 11 years). The median age of the 84 patients was 54 years (range 31 to 85 years). There were 41 women and 43 men. The most common diagnoses are presented in Table 1 and included 98 diagnoses in the 84 patients. The most common category was NP $(n=71)$; of these, 24 had NP in the leg with chronic back pain, followed by neuropathic facial pain in 18 (but not trigeminal neuralgia).

\section{Outcome data}

Opioid doses: The median dose, in MEs, was $220 \pm 470 \mathrm{mg} /$ day (range $20 \mathrm{mg} /$ day to $1990 \mathrm{mg} /$ day). The median dose in the group with low back pain and NP leg pain $(n=24)$ was $510 \mathrm{mg} /$ day. Patients $(\mathrm{n}=44)$ on a lower dose of opioids (less than $240 \mathrm{mg} \mathrm{ME} /$ day, median $80 \mathrm{mg} \mathrm{ME} /$ day) were compared with those $(\mathrm{n}=40)$ on a higher dose $(240 \mathrm{mg} /$ day or more, median $600 \mathrm{mg} \mathrm{ME} /$ day); no significant difference in demographics was found, but a significant difference favouring the lower dose group was found in the PDI sexual function scale $(\mathrm{P}=0.052)$ and $\mathrm{SF} 12 \mathrm{v} 2$ interference with work scale $(\mathrm{P}=0.0420)$ of all the outcome measures. The most frequently used opioid was oxycodone $(68 \%)$, followed by morphine $(19 \%)$, transdermal fentanyl (18\%), hydromorphone (12\%), methadone (2\%) and codeine $(1 \%)$ (some patients used more than one opioid).

The dosage of opioids remained stable in $84 \%$ of all opioids used ( $89 \%$ of short- and $79 \%$ of long-acting opioids) for at least one year (median 3.1 years) and, for many patients, much longer. Thus, tolerance and dose escalation were uncommon 


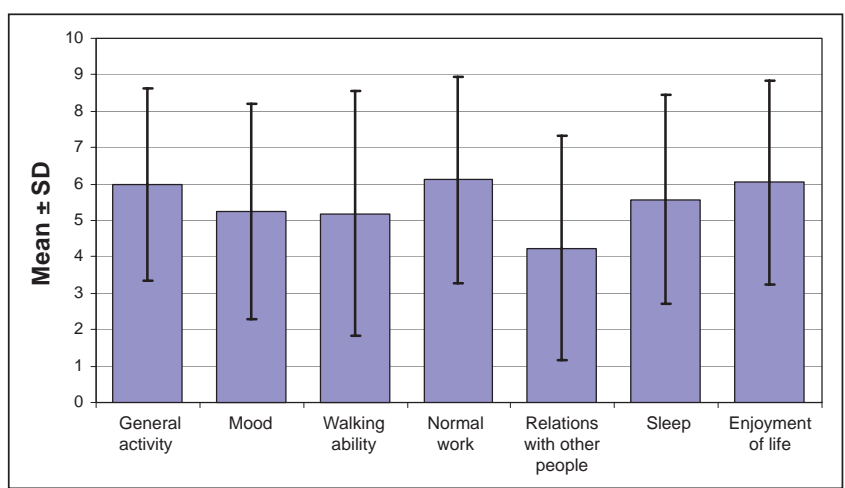

Figure 1) Mean Brief Pain Inventory interference scale ratings for the 84 surveyed patients

for both short- and long-acting preparations, which is consistent with the observations of others (24).

Pain ratings: Before opioids were introduced, all patients rated their pain as severe or very severe, and between 7 and 10 on an NRS. At the time of the present survey, pain severity as measured by the NRS and category scale indicated that $46 \%$ of patients (39/84) rated their pain as mild; that is, they chose the category 'mild' on the category scale or rated their pain as 3 or less on the NRS. A total of $49 \%$ of patients (41/84) rated their pain as moderate; that is, they chose 'moderate' on the category scale or rated their pain between 4 and 6 on the NRS. Four patients rated their pain as severe, at 7 or 8 on the NRS, but as less severe on the categorical scale and reduced from very severe. A total of $81 \%$ of patients (68/84) stated that, after using opioids, their pain improved by $50 \%$ or more, and $42 \%$ said they were $70 \%$ better.

Forty-two per cent of patients (35/84) said they had symptoms of physical withdrawal if they missed doses, $27 \%$ said they did not and $31 \%$ said they never missed a dose and, consequently, could not tell.

Adverse effects: A total of $74 \%$ of patients said they had no significant adverse effects. Twenty-six per cent of patients (22/84) reported a combined total of 40 significant adverse effects. Of these, the most common was constipation (22/40), followed by fatigue/drowsiness (4/40), dry mouth (3/40) and weight gain (2/40). Sweating, urinary retention, indigestion, memory loss, blurred vision, headache, rash, vomiting and reduced libido were each reported by one patient. The adverse effects were described as intolerable in seven instances; one instance of intolerable adverse effects was reported in each of the following categories: constipation, dry mouth, weight gain, urinary retention, memory impairment, vomiting and reduced libido.

A questionnaire regarding constipation was specifically devised and administered to all 84 patients because of the current view that tolerance to this particular adverse effect does not occur (32). A total of $71 \%$ of patients (60/84) said that they did not experience constipation or that it was mild. Twentynine per cent said that it was moderate or severe. Only one patient described the constipation as intolerable. A total of $40 \%$ recalled constipation being a worse problem at the onset of opioid administration. The treatment of constipation was variable. A total of $26 \%$ of patients (22/84) did not take anything for it, and of the rest, the following remedies were used either singly or in combination: docusate $(n=15)$, sennas $(n=14)$, bran $(n=13)$, prunes $(n=11)$, fruit $(n=9)$, fibre $(n=8)$, water $(n=7)$, psyllium $(n=5)$, vegetables $(n=4)$, lactulose $(n=3)$ and oranges

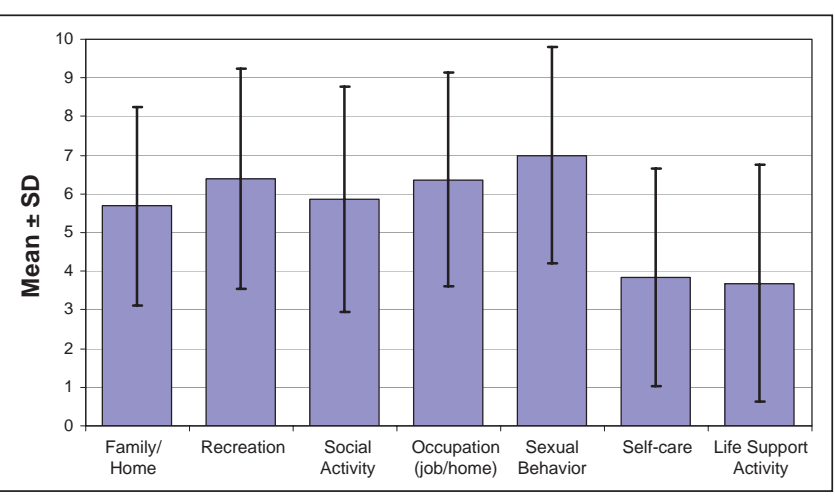

Figure 2) Mean Pain Disability Index ratings for the 84 surveyed patients

$(n=2)$; use of bisacodyl, apple sauce, magnesium citrate, exercise, flax, enemas, ex-lax (Novartis Consumer Health Inc, USA) and phosphate was reported by one patient each.

Patient satisfaction: Patients were asked whether they were satisfied with the degree of pain relief and the tolerability of the adverse effects. A total of $56 \%$ of patients (47/84) said they were satisfied and $44 \%$ said they were not. However, it was not determined whether the lack of satisfaction was related to inadequate pain relief or adverse effects; because of the paucity of intolerable adverse effects, it is reasonable to assume that lack of satisfaction was probably related to insufficient pain relief.

Depression and anxiety: Based on the scores on the Hospital Anxiety and Depression Scale, it was determined that 29\% of patients were depressed and 34\% were anxious. One patient had schizophrenia and two suffered from bipolar disorder. Six patients had a history of severe depression on entry into the present study. Statistically significant moderate correlations were found between BPI-I and depression $(r=0.64, \mathrm{P} \leq 0.001)$, BPI-I and anxiety $(\mathrm{r}=0.55, \mathrm{P} \leq 0.001)$, and anxiety and depression scores $(r=0.64, \mathrm{P} \leq 0.001)$.

Function: On the BPI-I (Figure 1) and PDI (Figure 2), ratings of the seven categories did not indicate severe functional impairment but demonstrated values in the moderate range.

Change in disability was rated in comparison with notations made before opioid treatment regarding whether the individual was bedridden/chair bound/not capable of any ADL; capable of ADL only; or able to do housework/childcare and go to work (Figure 3). Based on this comparison, the greatest change occurred in patients who moved from the categories of being bedridden/chair bound/not capable of any ADL to capable of ADL (50/78).

Quality of life: The ratings on the SF12v2 (Figure 4) were only slightly below normative values for the general age-related population and were not indicative of severe impairment of HRQL. The composite scores of overall physical health and overall mental health were slightly below normative values.

Infection and sexual function: No increase in infections (respiratory, urinary, gastrointestinal or other) was found compared with population norms. Sexual function was at least moderately impaired in $85 \%$ of patients, based on the NRS and the sexual behaviour scale of the PDI (Figure 2). Notably, unsatisfactory pain relief, age, concomitant drugs and diseases such as diabetes make it impossible to clearly relate this change in sexual function to opioids.

Problematic opioid use: Four patients in this group, with a history of alcohol dependence or bipolar disorder, exhibited problematic use of 


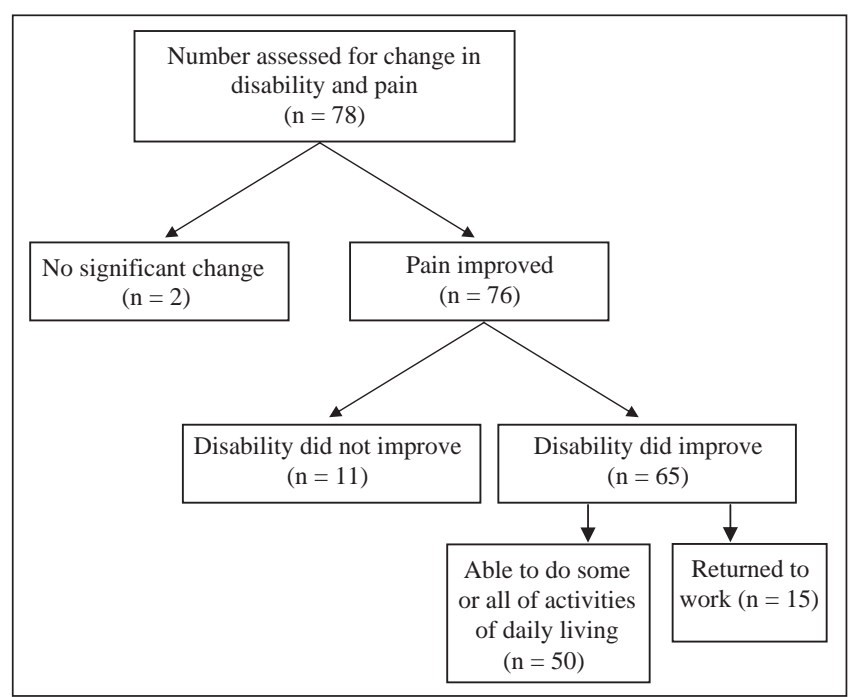

Figure 3) Change in disability status (ability to perform housework/ childcare, work or exercise) at the survey visit compared with the first visit before opioid therapy for patients whose pain relief improved while taking opioids

opioids early in treatment, with forged prescriptions, double doctoring and escalating doses, despite good pain relief. They have now been stable for several years, with good pain control following a discussion of guidelines or psychiatric treatment of the bipolar disorder.

\section{DISCUSSION}

The present study provides data supporting the long-term efficacy and safety of opioids for a selected group of patients with intractable CNCP, most of whom suffered from a variety of NP problems.

There is limited information in the literature about the longterm use of opioids in CNCP - reports are both observational (18-22) and epidemiological (23-25). Previous observational studies have indicated that opioids are effective over the long term $(18,21,22)$, but raised some concern about the lack of functional improvement and the abuse potential of these drugs $(19,20)$. Epidemiological studies have suggested problems with long-term use, including a low HRQL (23-25).

In the present sample of patients, the most common form of CNCP was NP. Of those with NP, the most frequent diagnosis was nerve root pain involving the fifth lumbar and/or first sacral nerve roots unilaterally or bilaterally, and was associated with chronic low back pain after failed surgeries.

The median long duration ( 3.5 years) on stable dosing argues in favour of the absence of further tolerance after maximal pain control is achieved. The median ME dose was $220 \mathrm{mg} /$ day with a maximum of $1990 \mathrm{mg} /$ day. The median dose was higher $(510 \mathrm{mg} /$ day) in the largest group of subjects, with back and neuropathic leg pain. These doses were higher than reported in most previous observational studies except Zenz et al (21). We do not believe this represented a hyperalgesic effect of opioids because there were no other clinical signs of this, such as pain that was more diffuse or less defined in quality, allodynia, hyperalgesia and/or a changed distribution beyond the pre-existing pain state (32). No difference was found in demographics for patients taking lower versus higher doses; the only differences found were better sexual function and decreased work interference in patients taking lower doses.

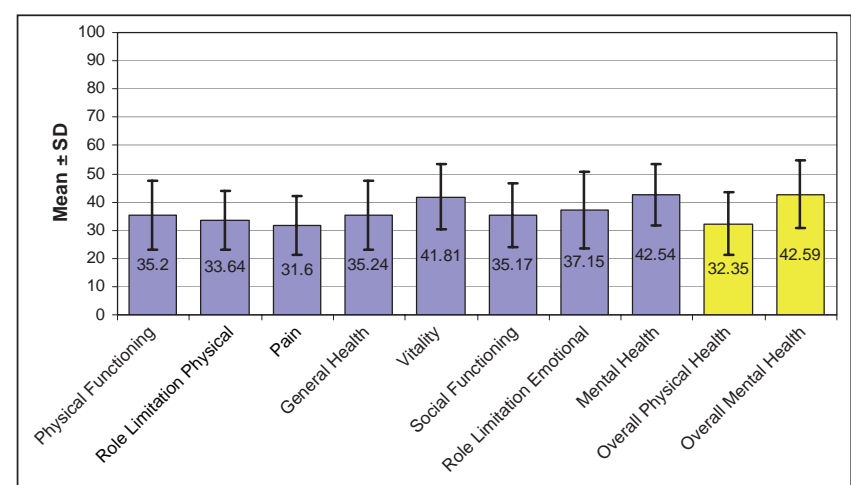

Figure 4) Mean Short-Form Health Survey 12, version 2, ratings for the 84 surveyed patients

An attempt was made to manage pain with only long-acting opioids, the most common of which was oxycodone. Patients were tried on a variety of opioids to determine optimal efficacy. Although oxycodone was the most commonly prescribed opioid, we can make no conclusion regarding relative efficacy based on a scientific comparison of opioids, such as might be determined in a head-to-head RCT. Although long-acting opioids are theoretically preferred for CNCP because they can produce a steady state and may be less likely to cause euphoria and addiction (32), we were unable to achieve optimal pain control using long-acting opioids alone in many patients.

Approximately equal numbers, for a total of $95 \%$ of patients, achieved either mild or moderate pain levels compared with their previous severe or very severe levels. A total of $81 \%$ of patients reported a $50 \%$ or more improvement in pain, with $42 \%$ stating that they had $70 \%$ or greater pain relief. Most claimed to experience no significant adverse effects. Of those who reported adverse effects, few stated that these were intolerable. Constipation has been considered to be an adverse effect to which tolerance does not occur (32). It has been suggested that this is because constipation is mediated by receptors in the bowel wall itself and is less affected by adaptations in the central nervous system (32). However, 70\% of patients reported that constipation was mild or absent. This finding raises the possibility that tolerance to constipation may occur in some patients after a longer time than other adverse effects. The management of constipation was notable only by the variety and combinations of measures used, but many patients used no measures at all.

Slightly more than one-half of patients expressed satisfaction with pain relief and the tolerability of adverse effects. We are not certain whether the reason for dissatisfaction was adverse effects or unsatisfactory pain relief because we did not separate these questions. It may be the latter, given the infrequent reports of intolerable adverse effects.

The majority of the scores for anxiety and depression were within the normal range. We did not find severe impairment in the functional capacity of most patients, but found that the patients' scores were in the moderate range. HRQL was just below normative values for individual scales, and for the general mental and physical health scales. Forty per cent of patients were older than 65 years of age or had significant concomitant illnesses such as diabetes and vascular disease, making the contribution of these nonpain-related conditions to reduced quality of life difficult to determine. 
Approximately one-quarter of patients reported no symptoms of physical withdrawal with missed doses, but many could not answer this question because they said that they never missed doses. There was no evidence in this sample of hyperalgesia or immune impairment. Sexual dysfunction was common, but this may be related to incompletely relieved pain, age, concomitant illnesses or other drugs, and not specifically to opioids.

The strengths of our study are the long-duration (median 8.2 years) follow-up of this group of intractable $\mathrm{CNCP}$ patients and frequent assessments made by the same observer. The weakness, as for all uncontrolled, nonblinded data, is the risk of bias in the observer and subjects. We would also advise caution when interpreting the external validity (ie, generalizability of these results to clinical practice) because our patients were undoubtedly a very select group with $\mathrm{CNCP}$ who received opioids for one year or more before study entry. It is very probable that nonresponders, or those with intolerable adverse effects due to opioids and problematic opioid use, did not elect to participate.

\section{CONCLUSIONS}

The long-term use of opioids over many years appears to be safe and effective for selected patients with intractable CNCP, many with NP, for whom all other treatments have failed. Generally, pain relief and the tolerability of adverse effects were reasonably good, considering the intractable nature of the

\section{REFERENCES}

1. Watson CPN, Babul N. Oxycodone relieves neuropathic pain: A randomized trial in postherpetic neuralgia. Neurology 1998;50:1837-41.

2. Harati Y, Gooch C, Swensen M, et al. Double blind randomized trial of tramadol for the treatment of the pain of diabetic neuropathy. Neurology 1998;50:1842-6.

3. Sindrup SH, Andersen G, Madsen C, et al. Tramadol relieves pain and allodynia in polyneuropathy; a randomized, double-blind, controlled trial. Pain 1999;83:85-90.

4. Rowbotham MC, Twilling L, Davies PS, et al. Oral opioid therapy for chronic peripheral and central neuropathic pain. N Engl J Med 2003; $13: 1223-32$.

5. Raja SJ, Haythornethwaite JA, Papagallo M, et al. Opioids versus antidepressants in postherpetic neuralgia; a placebo-controlled study. Pain 2002;94:215-24.

6. Watson CPN, Moulin D, Watt-Watson J, et al. Controlled-release oxycodone relieves neuropathic pain: A randomized controlled trial in painful diabetic neuropathy. Pain 2003;105;71-8.

7. Gimbel JS, Richards P, Portenoy RK. Controlled-release oxycodone for pain in diabetic neuropathy: A randomized controlled trial. Neurology 2003;60:927-34.

8. Boureau F, Legallicier P, Kabir-Ahmadi M. Tramadol in postherpetic neuralgia: A randomized, double-blind, placebo-controlled trial. Pain 2003;104:323-31.

9. Gilron I, Bailey JM, Tu D, Holden RR, Weaver DF, Houlden RL. Morphine, gabapentin or their combination for neuropathic pain. N Engl J Med 2005;352:1324-34.

10. Jaffe J. Opiates: Clinical aspects. In: Lowinson JH, Ruiz P, Millman RG, eds. Substance Abuse. A Comprehesive Textbook. Baltimore: Williams and Wilkins, 1992:186-94.

11. Sees KL, Clark KW. Opioid use in the treatment of chronic pain: Assessment of addiction. J Pain Symptom Manage 1993;8:257-64.

12. Savage SR. Long-term opioid therapy: Assessment of consequences and risks. J Pain Symptom Manage 1996;11:274-86.

13. Sacerdote P, Manfredi B, Manttegazza P, Panerai AE. Antinociceptive and immunosuppressive effects of opiate drugs: A structure-related activity study. Br J Pharmacol 1997;121:834-40.

14. Sjogren P, Olsen AK, Thomsen AB. Impaired neuropsychological performance in chronic non-malignant pain patients receiving long-term oral therapy. J Pain Symptom Manage 2000;19:100-8.

15. Mao J. Opioid-induced abnormal pain sensitivity; implications in clinical opioid therapy. Pain 2002;100:213-7.
CNCP in these patients. Significant and intolerable adverse effects were infrequent. Dissatisfaction with treatment appeared to be related to the degree of unrelieved pain rather than adverse effects. Few patients returned to work or had complete relief, but most reported improvement in ADL. Oxycodone was the preferred opioid of many patients, but determining whether this reflects a true advantage would require a head-tohead RCT. Tolerance to the analgesic effect was not a major concern with long- and short-acting opioids over time. Tolerance to constipation may occur, but after a longer time than other opioid adverse effects. Opioid combinations (longand short-acting forms of the same or different type) or a shortacting opioid may be preferred by some. Few patients were using adjuvant antidepressants or anticonvulsants. Physical withdrawal symptoms may not occur in all patients.

CONTRIBUTORS: CPNW conceived and designed this study and collected the data. All authors had access to the study data. JWW and MC provided statistical expertise, analyzed the data and critically reviewed the manuscript.

CONFLICT OF INTEREST STATEMENT: CPNW has received funding for clinical trials from Purdue Canada and speakers fees from Pfizer Canada and Merck Canada. All other authors have no conflict of interest to declare.
16. Rajogopal A, Vassilopoulou-Sellin R, Palmer JL, Kaur G, Brera E. Symptomatic hypogonadism in male survivors of cancer with chronic exposure to morphine. Cancer 2004;100:851-8.

17. Vallejo R, de Leon-Casasola O, Benyamin R. Opioid therapy and immunosuppression. A review. Am J Ther 2004;11:354-65.

18. Taub A. Opioid analgesics in the treatment of chronic intractable pain of non-neoplastic origin. In: Kitahata LM, Collins D, eds. Narcotic Analgesics in Anaesthesiology. Baltimore: Williams and Wilkins, 1982:199-208.

19. Portenoy RK, Foley RM. Chronic use of opioid analgesics in non-malignant pain. Report of 38 cases. Pain 1986;25:171-86.

20. Tennant FS, Robinson D, Sagherian A, Seecof R. Chronic opioid treatment of intractable non-malignant pain. Pain Manage 1988:18-36.

21. Zenz M, Strumpf M, Tryba M. Long-term oral opioid therapy in patients with nonmalignant pain. J Pain Symptom Manage 1992;7:69-77.

22. Watson CPN, Watt-Watson J, Chipman ML. Chronic non-cancer pain and the long term utility of opioids. Pain Res Manage 2004;9:19-24.

23. Becker N, Thomsen AB, Olsen AK, et al. Pain epidemiology and health related quality of life in chronic non-malignant pain patients referred to a Danish multidisciplinary pain center. Pain 2000;73:393-400.

24. Jensen MK, Thomsen AB, Hojsted J. 10 year follow-up of chronic non-malignant pain patients; opioid use, health related quality of life and health care utilization. Eur J Pain 2006;10:423-33.

25. Eriksen J, Sjogren P, Bruera E, et al. Critical issues in chronic non-cancer pain: An epidemiological study. Pain 2006;125:172-9.

26. Zigmond AS, Snaith RP. The hospital anxiety and depression scale. Acta Psychiatr Scand 1983;67:361-70.

27. Daut IE, Cleeland CS, Flanery RC. Development of the Wisconsin Brief Pain Questionnaire to assess pain in cancer and other diseases. Pain 1983;17:197-210.

28. Tait RC, Chibnall JT, Krause S. The Pain Disability Index: Psychometric properties. Pain 1990;40:171-82.

29. Chibnall JT, Tait RC. The Pain Disability Index: Factor structure and normative data. Arch Phys Med Rehabil 1994;75:1082-6.

30. Dworkin RH, Turk DC, Farrar JA, et al. Core outcome measures for pain clinical trials: IMMPACT recommendations. Pain 2005;113:9-19.

31. Ware JE, Kosinski M, Keller SD. A 12-item Short-Form Health Survey: Construction of scales and preliminary tests of reliability and validity. Medical Care 1996;34:220-33.

32. Ballantyne JC, Laforge SL. Opioid dependence and addiction during opioid treatment of chronic pain. Pain 2007;129:235-55. 


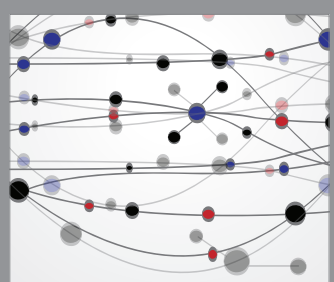

The Scientific World Journal
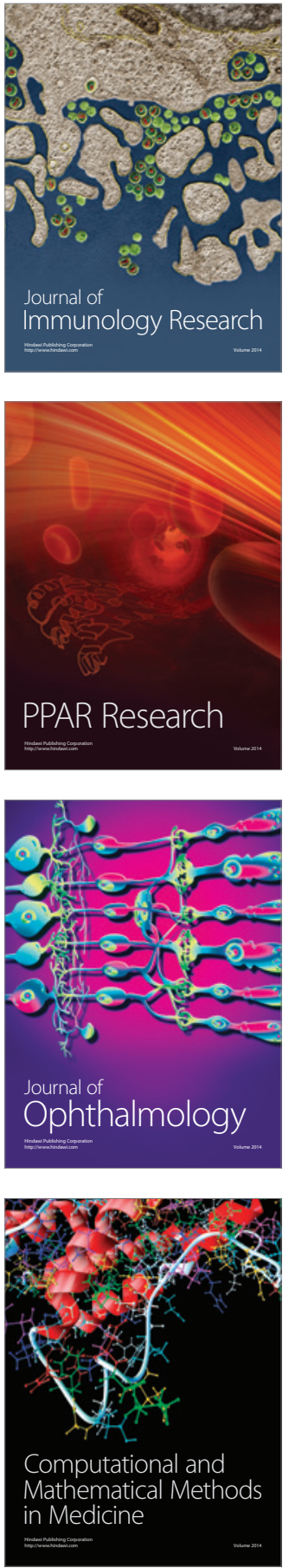

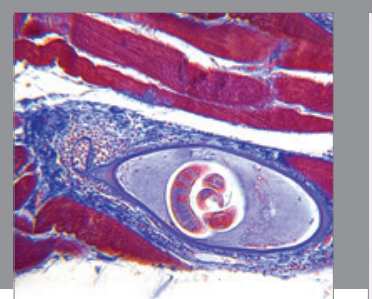

Gastroenterology Research and Practice

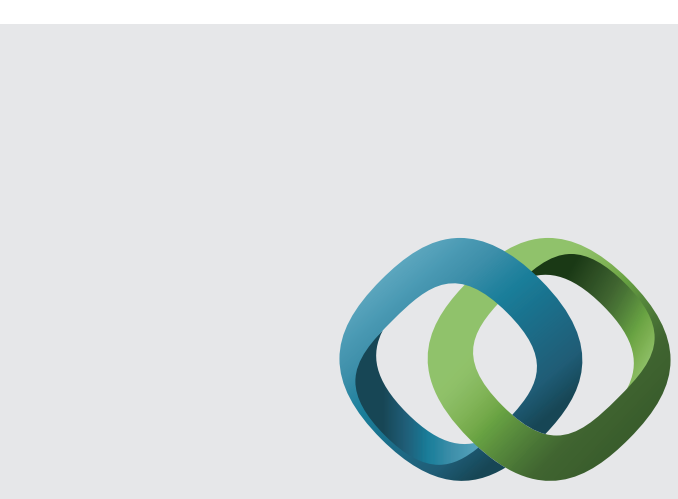

\section{Hindawi}

Submit your manuscripts at

http://www.hindawi.com
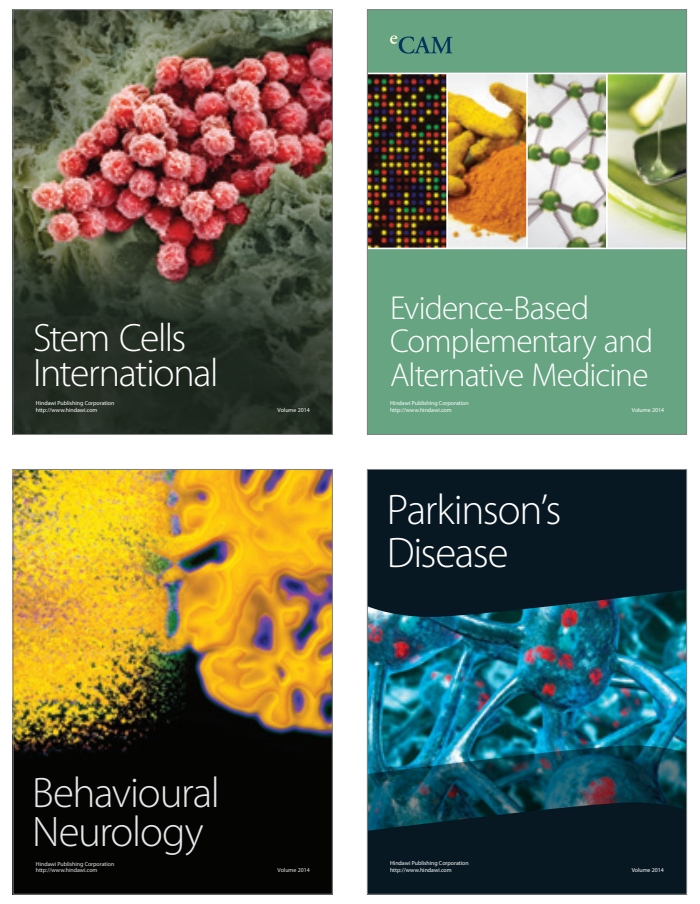
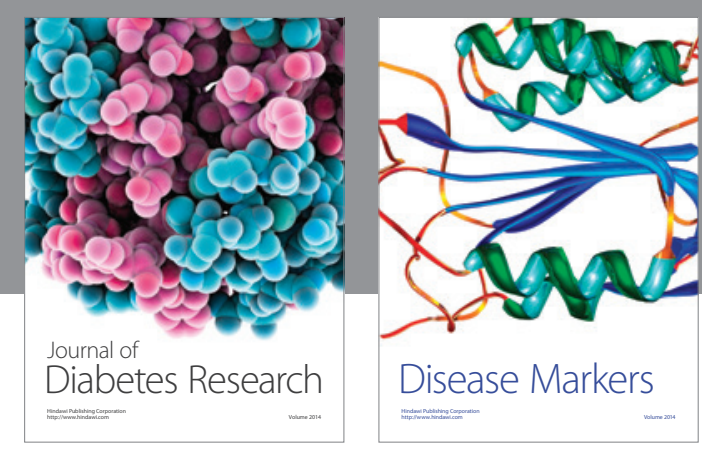

Disease Markers
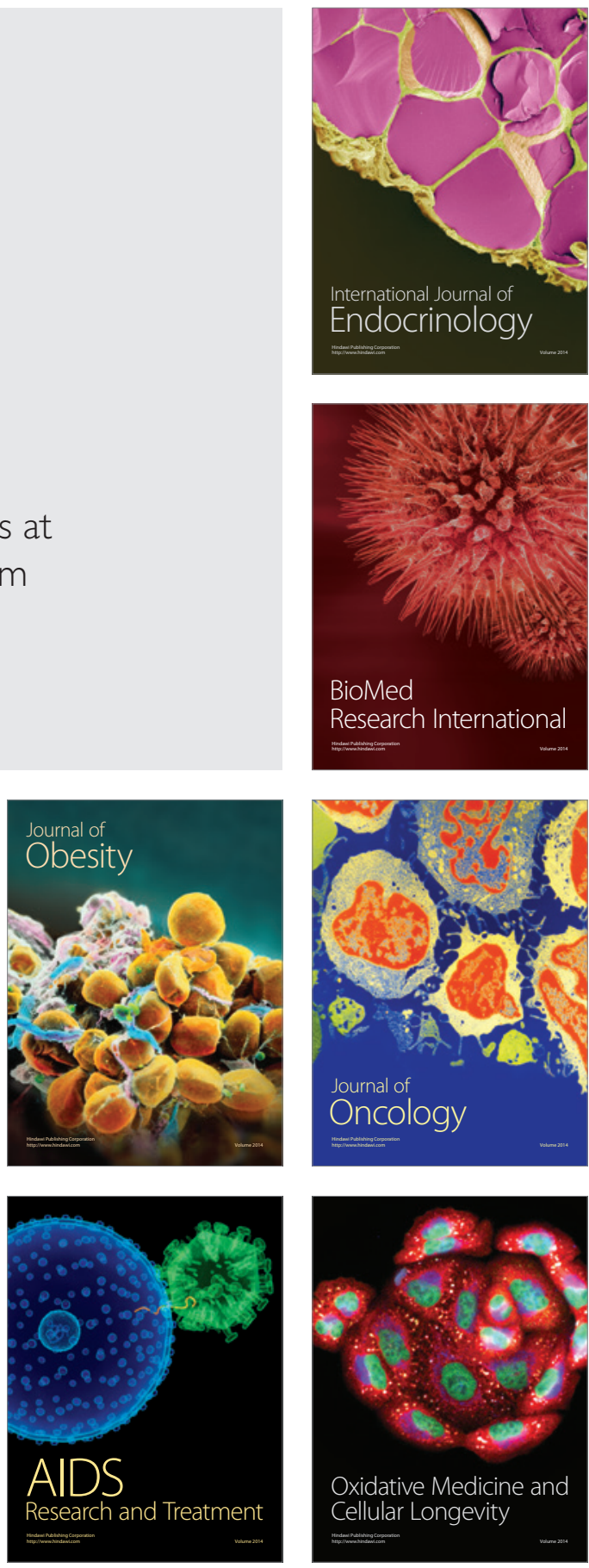